\title{
Systemic 5-bromo-2-deoxyuridine induces conditioned flavor aversion and c-Fos in the visceral neuraxis
}

\author{
Adam Kimbrough, ${ }^{1}$ Bumsup Kwon, ${ }^{1}$ Lisa A. Eckel, ${ }^{2}$ and Thomas A. Houpt ${ }^{1,3}$ \\ ${ }^{1}$ Department of Biological Science, Program in Neuroscience, Florida State University, Tallahassee, Florida 32306, USA; ${ }^{2}$ Department \\ of Psychology, Program in Neuroscience, Florida State University, Tallahassee, Florida, 32306, USA
}

\begin{abstract}
5-bromo-2-deoxyuridine ( $\mathrm{BrdU}$ ) is often used in studies of adult neurogenesis and olfactory learning, but it can also have toxic effects on highly proliferative tissue. We found that pairing Kool-Aid flavors with acute systemic injections of BrdU induced strong conditioned flavor aversions. Intermittent injections during Kool-Aid-glucose conditioning interfered with learning of a conditioned flavor-nutrient preference. Acute injection of BrdU also elevated plasma corticosterone levels and induced c-Fos in the visceral neuraxis. Thus, acute or intermittent systemic injections of BrdU (50-200 mg/kg) have aversive effects that may interfere with learning.
\end{abstract}

5-bromo-2-deoxyuridine (BrdU), a thymidine analog, incorporates into daughter DNA during the S-phase of cell division, marking new cells. BrdU is commonly used to label proliferation of new neurons in the mammalian brain during adult neurogenesis that may contribute to learning. Enhanced hippocampal neurogenesis, as labeled by BrdU, improves long-term spatial and visual recognition memory (Thuret et al. 2009). Additionally, olfactory learning impacts survival of newborn neurons (labeled with BrdU) after integration in the adult olfactory bulb (Mouret et al. 2008).

BrdU is often used in adult neurogenesis associative learning paradigms such as olfactory discrimination (as measured by habituation/disinhibition or by olfactory-cued reward task) (Mandairon et al. 2006; Mouret et al. 2008, 2009), olfactory associative learning (associating an odor with a hidden food reward) (Sultan et al. 2010), pair bonding in voles (Smith et al. 2001), and in nonassociative learning or declarative paradigms such as olfactory habituation (Magavi et al. 2005), olfactory enrichment (Rochefort and Lledo 2005; Veyrac et al. 2009), and hippocampaldependent spatial learning and object recognition (Thuret et al. 2009; Creer et al. 2010).

A potential confound for studies of adult neurogenesis in learning and memory is the toxicity of BrdU. Systemic injections of BrdU could have aversive consequences that might alter or influence learning. Because BrdU is incorporated into rapidly dividing cells, it can be toxic to highly proliferative tissues. BrdU has well-known teratogenic effects (Franz and Kleinebrecht 1982; Kolb et al. 1999). It also has been used for cancer treatment based on toxicity to and radiosensitization of mitotically active tumor cells (Lawrence et al. 1992).

BrdU is toxic to normal tissues with high proliferation rates, such as the skin and gastrointestinal tract. For example, in clinical trials of systemic BrdU in humans, BrdU caused rashes, mucositis, nail loss, and exfoliative dermatitis (Levin et al. 1995). BrdU is incorporated heavily in the intestine as early as $1 \mathrm{~h}$ following i.p. injection (Kriss and Revesz 1962), suggesting possible effects on endothelial proliferation within the lining of the gut. High doses of chronic BrdU (e.g., $200 \mathrm{mg} / \mathrm{kg} /$ day for $10 \mathrm{~d}$ ) led to weight loss in mice (Lawrence et al. 1992).

\footnotetext{
${ }^{3}$ Corresponding author.
}

E-mail houpt@neuro.fsu.edu; fax (850) 644-0989.

Article is online at http://www.learnmem.org/cgi/doi/10.1101//m.2176611.
BrdU is toxic to proliferating neurons at high doses in vitro (Caldwell et al. 2005). However, doses of $100-600 \mathrm{mg} / \mathrm{kg}$ i.p. have been found to be nontoxic to proliferating neurons in the hippocampus of adult rats (Cameron and McKay 2001). Nonetheless, BrdU might have aversive effects secondary to toxic effects on proliferative tissues in the periphery, such as in the gastrointestinal tract.

To determine whether BrdU has toxic effects that would impact behavior and neural processing, we assessed conditioned flavor aversion (CFA), interference with conditioned nutrientflavor preference (CFNP) learning, corticosterone release, and c-Fos following systemic injections of BrdU. We used doses of BrdU that are standard for visualization of proliferating neurons (i.e., $50-200 \mathrm{mg} / \mathrm{kg}$ ).

CFA is a form of associative learning in which an animal associates a novel flavor or taste with an aversive consequence, and subsequently avoids ingesting the flavor. CFA is a sensitive assay, such that a CFA can be observed in the absence of any other apparent toxic effect (Gamzu et al. 1985). The formation of a robust CFA often requires only one conditioning trial (Garcia and Kimeldorf 1957). Drugs and treatments with antimitotic activity can serve as potent aversive stimuli. Radiation (Garcia et al. 1955), cisplatin (Rudd et al. 1998), and cyclophosphamide (Mungarndee et al. 2006) all cause nausea and malaise in humans and are effective as a US in CFA paradigms.

To examine whether systemic BrdU could lead to a formation of a CFA, we paired ingestion of Kool-Aid/saccharin with a single i.p. injection of BrdU. Adult male rats $(n=24)$ were placed on a water restriction schedule. On conditioning day, rats were allowed a 10 -min access to $0.05 \%$ Kool-Aid mixed with $0.05 \%$ saccharin (counterbalanced, cherry and grape; $\mathrm{CS}+$ ). Rats drank an average of $5.2 \pm 0.3 \mathrm{~g}$, with no difference in intake among groups. Five min after access to the CS+ rats were divided into four groups and injected with one of four solutions: vehicle $(0.007 \mathrm{~N} \mathrm{NaOH}$, $0.15 \mathrm{M} \mathrm{NaCl}, 20 \mathrm{~mL} / \mathrm{kg})$, a low dose of BrdU $(50 \mathrm{mg} / \mathrm{kg})$, a high dose of $\mathrm{BrdU}(200 \mathrm{mg} / \mathrm{kg})$, or $\mathrm{LiCl}(0.15 \mathrm{M}, 76 \mathrm{mg} / \mathrm{kg})$ as a positive control. Following injections, water was returned overnight. The next day, two-bottle preference testing was begun with CS+ and an unconditioned Kool-Aid/saccharin (CS-) solution and continued for $14 \mathrm{~d}$ after conditioning. Preference score was calculated as CS + intake over total intake of $\mathrm{CS}+$ and CS - . Vehicle-injected rats were predicted to show a 50\% preference for the CS+ flavor over the CS- flavor; lower CS+ preference would indicate acquisition of a CFA. 
During two-bottle preference testing, the vehicle and low dose BrdU groups showed a preference close to $50 \%$, indicating equal intakes of $\mathrm{CS}+$ and CS-flavors. The $\mathrm{LiCl}$ and high-dose BrdU groups drank almost none of the CS+ flavor, indicating low preference and a strong CFA (Fig. 1). Two-way ANOVA revealed a significant effect of groups $\left(F_{(3,20)}=20.35, \quad P<\right.$ $0.00001)$, but no effect of days and no interaction. Post-hoc Newman Keuls revealed no significant difference between the low-dose BrdU and vehicle groups. Both the high-dose and $\mathrm{LiCl}$ groups displayed significantly lower CS + preferences than the vehicle group, and there was no significant difference in CS+ preference between the high dose $\mathrm{BrdU}$ and $\mathrm{LiCl}$ groups. Thus, the high dose BrdU and $\mathrm{LiCl}$ groups formed equivalent CFAs.

Although a single injection of $50 \mathrm{mg} / \mathrm{kg}$ BrdU failed to induce a CFA, multiple pairings of a CS and US can lead to a stronger CFA (Riley and Mastropaolo 1989). Therefore, we examined whether low-dose BrdU could induce a CFA after multiple pairings by giving three consecutive days of conditioning pairing Kool-Aid with $50 \mathrm{mg} / \mathrm{kg}$ injections of BrdU.

Rats $(n=12)$ were placed on water restriction and then conditioned on three consecutive days. On each conditioning day rats were allowed a 10 -min access to $0.05 \%$ Kool-Aid mixed with $0.05 \%$ saccharin $(\mathrm{CS}+$, counterbalanced cherry and grape). Rats were injected with either vehicle or BrdU $(50 \mathrm{mg} / \mathrm{kg}) 5$-min following CS + access. The day after the third conditioning day, expression of CFA was examined for the 6-d via two-bottle preference testing with the CS+ and CS-solutions.

Two-way ANOVA on conditioning intakes across the $3 \mathrm{~d}$ of conditioning showed that there was an effect of days $\left(F_{(2,20)}=\right.$ 28.12, $P<0.00001)$, but not group and no interaction. Intake of the BrdU group was significantly lower than the vehicle group on day 2 of conditioning, but not on days 1 or 3 (data not shown).

During two-bottle preference testing, neither the BrdU nor vehicle groups showed an overall average preference lower than $50 \%$. There was a main effect of group $\left(F_{(1,10)}=9.81, P<0.05\right)$, but no effect of days and no interaction. Therefore, intakes across the $6 \mathrm{~d}$ of preference testing were pooled for group comparison alone. The average CS+ preference of the BrdU group was significantly lower than the CS + preference of the vehicle group (51 \pm $3 \%$ vs. $69 \pm 5 \% ; P<0.01)$.

Although BrdU induced a CFA when explicitly paired with a novel flavor, BrdU is often administered across several days during

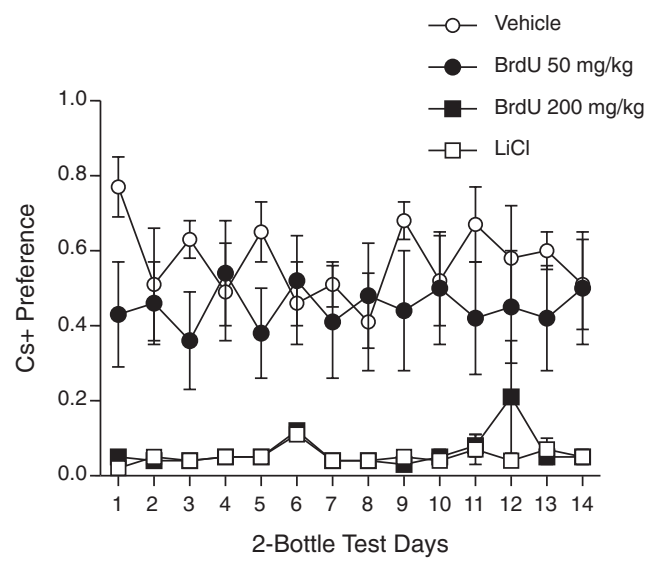

Figure 1. Preference for a Kool-Aid flavor $(\mathrm{CS}+)$ paired with drug treatment over an unpaired Kool-Aid flavor (CS - ) across $14 \mathrm{~d}$ of two-bottle tests. After one pairing of the CS + with either $200 \mathrm{mg} / \mathrm{kg} \mathrm{BrdU}$ (black squares) or $\mathrm{LiCl}$ (white squares), rats showed a significantly lower preference compared with vehicle-treated rats (white circles). CS+ preference in rats treated with $50 \mathrm{mg} / \mathrm{kg} \mathrm{BrdU}$ (black circles) was not significantly lower than in vehicle-treated rats. a distinct learning protocol to assess learning-associated neurogenesis. A typical neurogenesis study using BrdU injections often involves multiple injections over the course of a 24- to 48-h period. Multiple injections allow labeling of cells that are going through S-phase divisions across the day, and thus incorporating BrdU at different times (Cameron and McKay 2001). These studies often result in a total dose of BrdU ranging from $100 \mathrm{mg} / \mathrm{kg}$ to $300 \mathrm{mg} / \mathrm{kg}$ per day. If BrdU has aversive effects, then a typical neurogenesis protocol of BrdU administration might interfere with the learning under study.

To determine whether BrdU can disrupt learning, we administered BrdU concurrently with CFNP acquisition. CFNP learning is a robust form of olfactory learning in which a flavor is paired with nutrient content (e.g., glucose), producing a strong preference for the nutrient-paired flavor over non-nutritive flavors (Ackroff and Sclafani 1991; Sclafani et al. 1993; Ackroff et al. 2009). Disruption of CFNP learning by BrdU injections would indicate an alteration of learning following BrdU injection.

Rats $(n=16)$ were assigned to two groups of eight. One group received vehicle injections, while the other group received BrdU injections $(100 \mathrm{mg} / \mathrm{kg})$. Injections were given at $2 \mathrm{~h}$ after lights off and repeated every $12 \mathrm{~h}$ for a total of four injections over $48 \mathrm{~h}$. Thus, rats received intermittent injections of BrdU at a dose that is not neurotoxic (Cameron and McKay 2001).

Immediately following the first injection, rats were given 48 -h access to two bottles: a solution of $8 \%$ glucose, $0.05 \%$ sodium saccharin, and $0.05 \%$ Kool-Aid (CS +, grape or cherry counterbalanced); and water. Intake was measured every $12 \mathrm{~h}$. At $24 \mathrm{~h}$, solutions were refilled and bottle positions were switched. Following $48 \mathrm{~h}$ of conditioning, two-bottle preference testing with both $\mathrm{CS}+$ /saccharin (without glucose) and unconditioned Kool-Aid/ saccharin $(\mathrm{CS}-)$ solutions was begun and continued for 14 consecutive days.

During 48-h conditioning the cumulative intake of CS + by vehicle-treated rats increased over the course of $48 \mathrm{~h}$; water intake remained low. The BrdU-treated rats had slightly increased intake of water over $48 \mathrm{~h}$, while the CS+ intake remained low (Fig. 2A). There were significant effects of group and hour during conditioning and an interaction $\left(F_{(3,42)}=73.56, P<0.0001\right)$, such that the $\mathrm{CS}+$ intake of the BrdU group was significantly lower than the vehicle group at all time points.

During two-bottle preference testing there was an effect of group $\left(F_{(1,14)}=18.86, P<0.001\right)$ with a significant difference between BrdU and vehicle-treated rats on all days (Fig. 2B). Thus, concurrent administration of BrdU during CNFP conditioning prevented a CNFP from forming and instead led to CFA acquisition.

We also determined whether BrdU had acute behavioral or physiological effects. After injection of a malaise-inducing toxin, rats display "lying-on-belly" (LOB) by maintaining an extended prone posture on the cage floor (Bernstein et al. 1992). Six rats were observed for LOB for $1 \mathrm{~h}$ following i.p. injection of vehicle, $\mathrm{BrdU}(200 \mathrm{mg} / \mathrm{kg})$, or $\mathrm{LiCl}(76 \mathrm{mg} / \mathrm{kg})$. Every rat received each treatment counterbalanced across days, with at least $3 \mathrm{~d}$ between injections. $\mathrm{LiCl}$ injections caused $\mathrm{LOB}$ in all rats (6/6) with an average latency of $18 \pm 2 \mathrm{~min}$, while LOB after BrdU was observed at 46 min post-injection in one rat $(1 / 6)$. LOB was not observed after vehicle injections.

Although we did not observe an acute behavioral effect, we examined corticosterone levels at $1 \mathrm{~h}$ after BrdU injection. $\mathrm{LiCl}$ injection elevates plasma corticosterone in rats (Hennessy et al. 1976; Smotherman et al. 1976; Spencer et al. 2005) as does cyclophosphamide (Di Renzo et al. 1977). Rats ( $n=12$ /group) received an i.p. injection of vehicle or BrdU $(200 \mathrm{mg} / \mathrm{kg})$. One hour later rats were anesthetized with $\mathrm{CO}_{2}$, decapitated, and trunk blood was collected. Plasma was processed for rat corticosterone by 

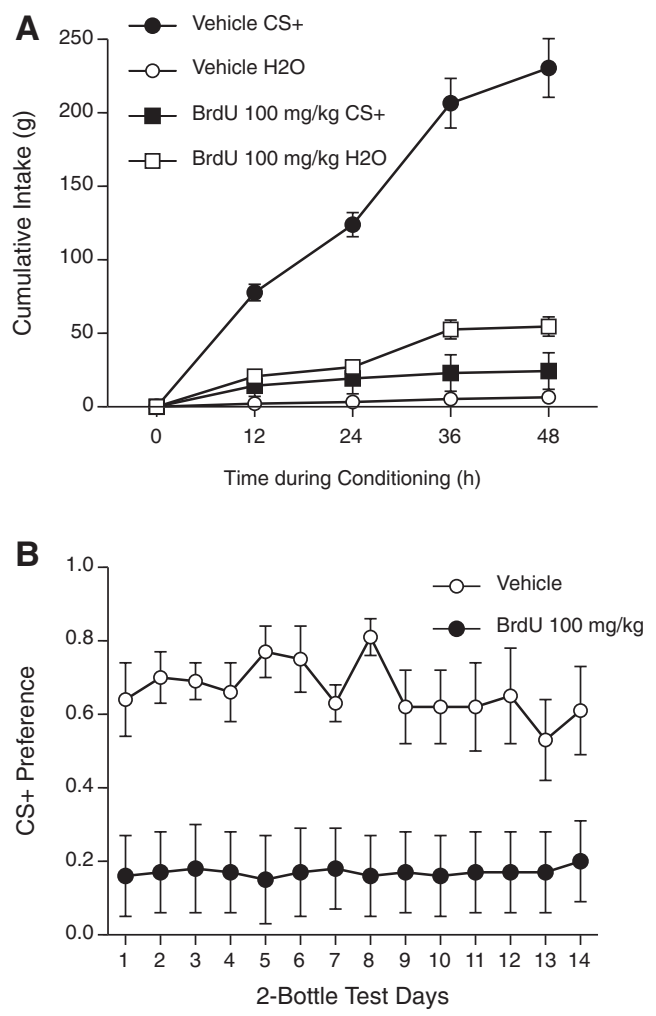

Figure 2. (A) Cumulative intake of Kool-Aid flavor mixed with glucose (CS+, black symbols) or water (white symbols) by rats injected with vehicle (circles) or BrdU (100 mg/kg, squares) at 12 -h intervals across a 48-h conditioning period. Vehicle-treated rats showed robust intake of the CS + with almost no water consumption; BrdU-treated rats showed a preference for water over the CS+. (B) Preference for the CS+ flavor mixed with saccharin over an unpaired flavor (CS-) across $14 \mathrm{~d}$ of twobottle preference tests. Vehicle-treated rats (white circles) showed a strong preference for the $\mathrm{CS}+$, while BrdU-treated rats (black circles) showed an aversion toward the CS+.

radioimmunoassay (Coat-A-Count, Siemens). BrdU caused a significant increase $(P<0.05)$ in plasma corticosterone levels $(114.6 \pm$ $27.8 \mathrm{ng} / \mathrm{mL})$ compared with vehicle $(41.2 \pm 10.9 \mathrm{ng} / \mathrm{mL})$.

Finally, we explored whether BrdU would induce c-Fos expression patterns in the visceral neuraxis comparable to other toxins. We examined c-Fos in the visceral neuraxis at 1 and $3 \mathrm{~h}$ after BrdU injection in the nucleus of the solitary tract (NTS), the parabrachial nucleus (PBN), and the central amgydala (CeA).

Rats were injected with vehicle ( $n=4$ /time point) or with $\mathrm{BrdU}(n=4 /$ time point, $200 \mathrm{mg} / \mathrm{kg})$. At 1 and $3 \mathrm{~h}$ after injection, rat brains were removed and processed for c-Fos immunoreactivity as previously described (Kwon et al. 2008).

At $1 \mathrm{~h}$ after injection there was significantly more c-Fos expression in BrdU-vs. vehicle-treated rats in the NTS $(7.4 \pm 1.8$ vs. $2.8 \pm$ $0.9, P<0.05)$ but not the PBN or CeA. At $3 \mathrm{~h}$ after injection there was significantly greater c-Fos expression in BrdU- vs. vehicletreated rats in the NTS $(15.3 \pm 5.8$ vs. $3.1 \pm 0.6 ; P<0.05)$ and CeA $(26.2 \pm 8.3$ vs. $5.7 \pm 1.3 ; P<0.05)$, but not in the PBN $(11.8 \pm 4.3$ vs. $4.0 \pm 1.0 ; P<0.07$ ) (Fig. 3). Much of the c-Fos in the NTS region was located near the border of the NTS and area postrema (AP), although very little c-Fos was seen in the AP itself. In the PBN, c-Fos was localized to the lateral and external subnuclei.

BrdU activation of the visceral neuraxis is consistent with an effect on the gastrointestinal tract and visceral afferents (e.g., the vagus nerve) or chemoreceptors of the area postrema (Bernstein et al. 1992; Saper 2002). For example, c-Fos response in the brain following LiCl injection occurs heavily in the NTS, PBN and CeA (Yamamoto et al. 1992; Swank and Bernstein 1994; Spencer and Houpt 2001; Rinaman and Dzmura 2007). Cisplatin induces similar c-Fos expression in the NTS and AP, which relies on vagal input (Horn et al. 2004, 2007; Horn 2009). Thus, expression of c-Fos in the visceral neuraxis is an indicator of visceral stimulation.

In conclusion, these results demonstrate that systemic BrdU has aversive effects on rats even in the absence of observable behavioral effects. Systemic injections of a high dose of BrdU $(200 \mathrm{mg} / \mathrm{kg}$, i.p.) paired with a flavor induced a profound CFA, while a lower dose $(50 \mathrm{mg} / \mathrm{kg})$ had a milder aversive effect after multiple pairings. Furthermore, BrdU administration (as in a typical adult neurogenesis paradigm) during acquisition of an olfactory-based CFNP was disruptive to the learning. Additionally, we showed that injections of BrdU stimulated corticosterone release and increased c-Fos expression in the NTS and CeA, suggesting that BrdU treatment activates the hypothalamic-pituitary-adrenal axis and visceral neuraxis in parallel with its aversive effects.

We have not identified the mechanism of BrdU's aversive action. BrdU is incorporated into mitotically active cells, and can therefore have a cytotoxic effect on rapidly dividing tissues (Caldwell et al. 2005). Thus, BrdU could have an effect similar to other treatments that damage proliferating cells (e.g., wholebody irradiation (Garcia et al. 1955), cisplatin (Rudd et al. 1998), or cyclophosphamide (Mungarndee et al. 2006). The gastrointestinal tract, with rapid turnover of cells, shows a high rate of BrdU incorporation (Kriss and Revesz 1962), and thus is a potential site of BrdU action that could lead to aversive effects and CFA acquisition.

The doses of BrdU typically used in studies of adult neurogenesis are above the threshold required for aversive effects (Cameron and McKay 2001). Thus, there is the potential for aversive effects of BrdU to interact with or confound learning. Others have also shown that BrdU may interfere with learning (Komissarova et al. 2010). Olfactory learning may be especially

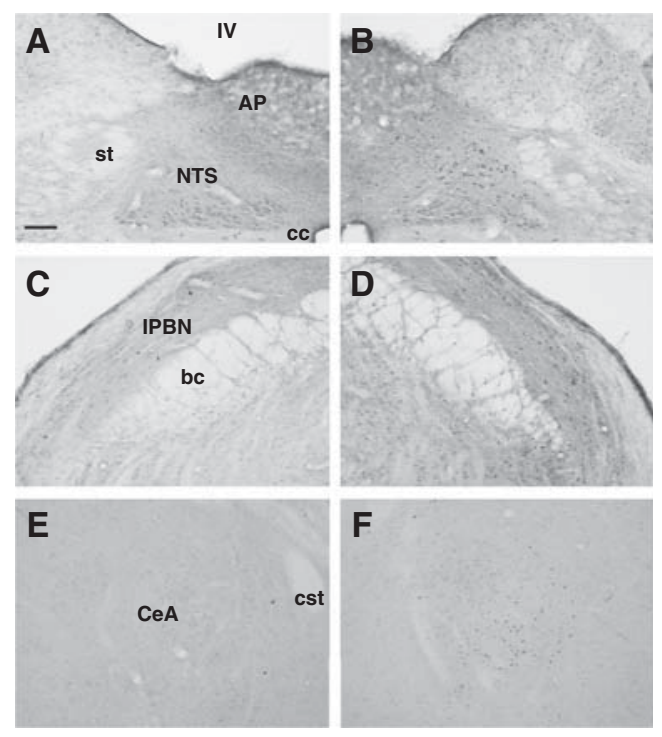

Figure 3. Photomicrographs of $\mathrm{c}$-Fos expression $3 \mathrm{~h}$ after injection of vehicle $(A, C, E)$ or BrdU $(200 \mathrm{mg} / \mathrm{kg} ; B, D, F)$ in the NTS $(A, B)$, PBN $(C, D)$, and $\mathrm{CeA}(E, F)$. Scale bar in $A$ : 100 microns. (IV) Fourth ventricle; (cC) central canal; (st) solitary tract; (AP) area postrema; (NTS) nucleus of the solitary tract; (bc) brachium conjectivum; (IPBN) lateral parabrachial nucleus; (cst) commisural stria terminalis; (CeA) central nucleus of the amygdala. 
susceptible to aversive interference, given the ease in which odor or flavor aversions can be acquired. Stimuli producing visceral toxic effects can be strongly associated with flavor, taste, and ingestion; other extereoceptive stimuli may not be as strongly associated with the aversive effects of BrdU injections (Garcia and Ervin 1968).

BrdU injections may disrupt other types of learning due to elevated corticosterone levels, such as disruption of hippocampaldependant spatial memory by acute stress (Cazakoff et al. 2010). Furthermore, BrdU would most likely interfere with learning when administered during the acquisition period. There is no reason to believe prior administration of BrdU (i.e., to label mature neurons that proliferated days or weeks earlier) would interfere with subsequent learning.

\section{References}

Ackroff K, Sclafani A. 1991. Flavor preferences conditioned by sugars: Rats learn to prefer glucose over fructose. Physiol Behav 50: 815-824.

Ackroff K, Dym C, Yiin YM, Sclafani A. 2009. Rapid acquisition of conditioned flavor preferences in rats. Physiol Behav 97: 406-413.

Bernstein IL, Chavez M, Allen D, Taylor EM. 1992. Area postrema mediation of physiological and behavioral effects of lithium chloride in the rat. Brain Res 575: $132-137$.

Caldwell MA, He X, Svendsen CN. 2005. 5-Bromo-2'-deoxyuridine is selectively toxic to neuronal precursors in vitro. Eur J Neurosci 22 2965-2970.

Cameron HA, McKay RD. 2001. Adult neurogenesis produces a large pool of new granule cells in the dentate gyrus. J Comp Neurol 435: $406-417$.

Cazakoff BN, Johnson KJ, Howland JG. 2010. Converging effects of acute stress on spatial and recognition memory in rodents: A review of recen behavioural and pharmacological findings. Prog Neuropsychopharmacol Biol Psychiatry 34: 733-741.

Creer DJ, Romberg C, Saksida LM, van Praag H, Bussey TJ. 2010. Running enhances spatial pattern separation in mice. Proc Natl Acad Sci 107: $2367-2372$.

Di Renzo G, Schettini G, Preziosi P. 1977. Effects of some antineoplastic agents on plasma levels of corticosterone, prolactin and thyroid stimulating hormone. Arch Int Pharmacodyn Ther 230: 324-329.

Franz J, Kleinebrecht J. 1982. Teratogenic and clastogenic effects of BUdR in mice. Teratology 26: 195-202.

Gamzu E, Vincent G, Boff E. 1985. A pharmacological perspective of drugs used in establishing conditioned food aversions. Ann N Y Acad Sci 443: 231-249.

Garcia J, Kimeldorf DJ. 1957. Temporal relationship within the conditioning of a saccharine aversion through radiation exposure. J Comp Physiol Psychol 50: 180-183.

Garcia J, Ervin FR. 1968. Gustatory-visceral and telereceptor-cutaneous conditioning-adaption in internal and external milieus. Commun Behav Biol Part A: 389-415.

Garcia J, Kimeldorf DJ, Koelling RA. 1955. Conditioned aversion to saccharin resulting from exposure to gamma radiation. Science 122: 157-158.

Hennessy JW, Smotherman WP, Levine S. 1976. Conditioned taste aversion and the pituitary-adrenal system. Behav Biol 16: 413-424.

Horn CC. 2009. Brain Fos expression induced by the chemotherapy agent cisplatin in the rat is partially dependent on an intact abdominal vagus. Auton Neurosci 148: 76-82.

Horn CC, Richardson EJ, Andrews PL, Friedman MI. 2004. Differential effects on gastrointestinal and hepatic vagal afferent fibers in the rat by the anti-cancer agent cisplatin. Auton Neurosci 115: 74-81.

Horn CC, Ciucci M, Chaudhury A. 2007. Brain Fos expression during $48 \mathrm{~h}$ after cisplatin treatment: Neural pathways for acute and delayed visceral sickness. Auton Neurosci 132: 44-51.

Kolb B, Pedersen B, Ballermann M, Gibb R, Whishaw IQ. 1999. Embryonic and postnatal injections of bromodeoxyuridine produce agedependent morphological and behavioral abnormalities. J Neurosci 19: $2337-2346$

Komissarova NV, Tiunova AA, Anokhin KV. 2010. Selective impairments to memory consolidation in chicks produced by $5^{\prime}$-iodo-2'-deoxyuridine. Neurosci Behav Physiol 40: 215-223.

Kriss JP, Revesz L. 1962. The distribution and fate of bromodeoxyuridine and bromodeoxycytidine in the mouse and rat. Cancer Res 22: 254-265.
Kwon B, Goltz M, Houpt TA. 2008. Expression of AP-1 family transcription factors in the amygdala during conditioned taste aversion learning: Role for Fra-2. Brain Res 1207: 128-141.

Lawrence TS, Davis MA, Maybaum J, Mukhopadhyay SK, Stetson PL, Normolle DP, McKeever PE, Ensminger WD. 1992. The potential superiority of bromodeoxyuridine to iododeoxyuridine as a radiation sensitizer in the treatment of colorectal cancer. Cancer Res 52: 3698-3704.

Levin VA, Prados MR, Wara WM, Davis RL, Gutin PH, Phillips TL, Lamborn K, Wilson CB. 1995. Radiation therapy and bromodeoxyuridine chemotherapy followed by procarbazine, lomustine, and vincristine for the treatment of anaplastic gliomas. Int J Radiat Oncol Biol Phys 32: 75-83.

Magavi SS, Mitchell BD, Szentirmai O, Carter BS, Macklis JD. 2005. Adult-born and preexisting olfactory granule neurons undergo distinct experience-dependent modifications of their olfactory responses in vivo. J Neurosci 25: 10729-10739.

Mandairon N, Sacquet J, Garcia S, Ravel N, Jourdan F, Didier A. 2006 Neurogenic correlates of an olfactory discrimination task in the adult olfactory bulb. Eur J Neurosci 24: 3578-3588.

Mouret A, Gheusi G, Gabellec MM, de Chaumont F, Olivo-Marin JC, Lledo PM. 2008. Learning and survival of newly generated neurons: When time matters. J Neurosci 28: 11511-11516.

Mouret A, Lepousez G, Gras J, Gabellec MM, Lledo PM. 2009. Turnover of newborn olfactory bulb neurons optimizes olfaction. J Neurosci 29: $12302-12314$

Mungarndee SS, Lundy RF Jr, Norgren R. 2006. Central gustatory lesions and learned taste aversions: Unconditioned stimuli. Physiol Behav 87: $542-551$.

Riley AL, Mastropaolo JP. 1989. Long-delay taste-aversion learning - Effects of repeated trials and 2-bottle testing conditions. Bull Psychon Soc 27: $145-148$.

Rinaman L, Dzmura V. 2007. Experimental dissociation of neural circuits underlying conditioned avoidance and hypophagic responses to lithium chloride. Am J Physiol Regul Integr Comp Physiol 293: R1495-R1503.

Rochefort C, Lledo PM. 2005. Short-term survival of newborn neurons in the adult olfactory bulb after exposure to a complex odor environment. Eur J Neurosci 22: 2863-2870.

Rudd JA, Ngan MP, Wai MK. 1998. 5-HT3 receptors are not involved in conditioned taste aversions induced by 5-hydroxytryptamine, ipecacuanha or cisplatin. Eur J Pharmacol 352: 143-149.

Saper CB. 2002. The central autonomic nervous system: Conscious visceral perception and autonomic pattern generation. Annu Rev Neurosci 25: 433-469.

Sclafani A, Cardieri C, Tucker K, Blusk D, Ackroff K. 1993. Intragastric glucose but not fructose conditions robust flavor preferences in rats. Am J Physiol 265: R320-R325.

Smith MT, Pencea V, Wang Z, Luskin MB, Insel TR. 2001. Increased number of BrdU-labeled neurons in the rostral migratory stream of the estrous prairie vole. Horm Behav 39: 11-21.

Smotherman WP, Hennessy JW, Levine S. 1976. Plasma corticosterone levels during recovery from $\mathrm{LiCl}$ produced taste aversions. Behav Biol 16: $401-412$.

Spencer CM, Houpt TA. 2001. Dynamics of c-fos and ICER mRNA expression in rat forebrain following lithium chloride injection. Brain Res Mol Brain Res 93: 113-126.

Spencer CM, Jahng JW, Ryu V, Houpt TA. 2005. Lithium-induced gene expression of inducible cyclic adenosine monophosphate early repressor in the rat adrenal gland. J Neurosci Res 82: 273-282.

Sultan S, Mandairon N, Kermen F, Garcia S, Sacquet J, Didier A. 2010. Learning-dependent neurogenesis in the olfactory bulb determines long-term olfactory memory. FASEB J 24: 2355-2363.

Swank MW, Bernstein IL. 1994. c-Fos induction in response to a conditioned stimulus after single trial taste aversion learning. Brain Res 636: 202-208.

Thuret S, Toni N, Aigner S, Yeo GW, Gage FH. 2009 Hippocampus-dependent learning is associated with adult neurogenesis in MRL/MpJ mice. Hippocampus 19: 658-669.

Veyrac A, Sacquet J, Nguyen V, Marien M, Jourdan F, Didier A. 2009. Novelty determines the effects of olfactory enrichment on memory and neurogenesis through noradrenergic mechanisms. Neuropsychopharmacology 34: 786-795.

Yamamoto T, Shimura T, Sako N, Azuma S, Bai WZ, Wakisaka S. 1992. C-fos expression in the rat brain after intraperitoneal injection of lithium chloride. Neuroreport 3: 1049-1052.

Received February 18, 2011; accepted in revised form March 2, 2011. 


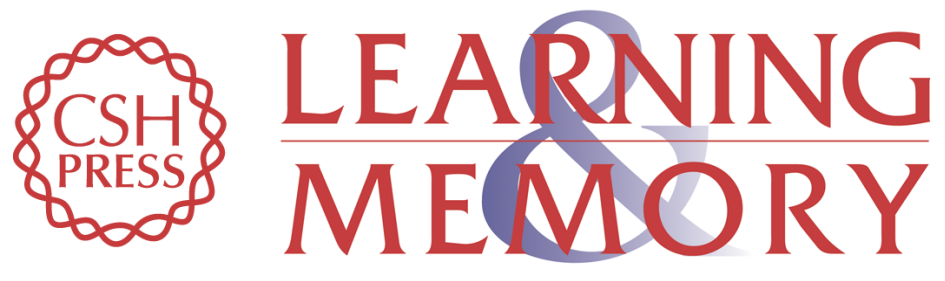

\section{Systemic 5-bromo-2-deoxyuridine induces conditioned flavor aversion and $c-F o s$ in the visceral neuraxis}

Adam Kimbrough, Bumsup Kwon, Lisa A. Eckel, et al.

Learn. Mem. 2011, 18:

Access the most recent version at doi:10.1101//m.2176611

References This article cites 43 articles, 8 of which can be accessed free at:

http://learnmem.cshlp.org/content/18/5/292.full.html\#ref-list-1

License

Email Alerting Receive free email alerts when new articles cite this article - sign up in the box at the Service top right corner of the article or click here. 